\title{
Photojournalism as a Core Journalism Course Unit: Challenges and Solutions. A Survey of Some Universities in Rwanda
}

\author{
Henry Mapesa \\ Assistant Lecturer, Faculty of Social Sciences, Department of Journalism, Mount Kenya University Kigali Campus, P. O. Box 5826, Kigali \\ Rwanda
}

\begin{abstract}
Photography in journalism plays a big role in society as the art and science of a universal means of communication. Most scholars attributed photography communication as the best archive for all aspects of history and news stories. Although it's crucial in journalism, photography is mostly mistaken to be not a professional course. At University level, photography is not given adequate time by students during their studies which results to many journalism students graduating without the practical knowledge and skills of using scarce digital professional still photo cameras and new editing software in the country. Using the available data and documentations, this paper analyzes the policy of photography being a compulsory unit among colleges of journalism to all students. It has been recommended that photography be granted a compulsory practical status to all students training journalism at University from diploma, degree and master levels. The last section of this article suggests several paradigms of the learning and teaching of photography for journalism.
\end{abstract}

Keywords: Definitions of photography, a universal means of communication, photographs inform and keep memories

\section{Introduction}

The word photography comes from two ancient Greek words: photo, for "light," and graph, for "drawing." "Drawing with light" is a way of describing photography. When a photograph is made, light or some other form of radiant energy, such as $\mathrm{X}$ rays, is used to record a picture of an object or scene on a light-sensitive surface. Early photographs were called sun pictures, because sunlight itself was used to create the image. Mankind has been a maker of images at least since the cave paintings of some 20,000 years ago. With the invention of photography, a realistic image that would have taken a skilled artist hours or even days to draw could be recorded in exact detail within a fraction of a second.

Today, photography has become a powerful means of communication and a mode of visual expression that touches human life in many ways. For example, photography has become popular as a means of crystallizing memories. Most of the billions of photographs taken today are snapshots casual records to document personal and national events such as news, independence days, dialogues, politics, evidence in courts, national parks, birthdays, and weddings, sport, disasters, culture.

Photographs are used extensively by newspapers, magazines, books, and television to convey information and advertise products and services. Practical applications of photography are found in nearly every human endeavor from astronomy to medical diagnosis to industrial quality control. Photography extends human vision into the realm of objects that are invisible because they are too small or too distant, or events that occur too rapidly for the naked eye to detect. A camera can be used in locations too dangerous for humans. Photographs can also be objects of art that explore the human condition and provide aesthetic pleasure. For millions of people, photography is a satisfying hobby or a rewarding career.
Photojournalism has long been the principal visual medium through which we have come to understand important events unfolding beyond our immediate perceptual horizon. (Jason Hill)

(Nwanyelugo and Nwadiukwu 2009:89) asserts that, while the photographer operates more or less in "aware" or familiar zone, the photojournalist covers the "aware," "semiaware" and "candid" domains with a sharp sense of news, information, education and entertainment. What makes a photographer different from a photojournalist is that a photographer takes picture of nouns (people, places, things), while photojournalist shoots actions or dynamic verbs (kicks, explodes, cries etc.). Where a photojournalist takes a picture of nouns then it must be a standard portrait (of people) or places, proposed zoning areas or construction sites, and these must seek to tell story in clear details.

According to Suuny E. Udeze (1995) he re-echoed the popular saying in photojournalism that a picture is worth more than a thousand words (Udofia, 1988, p.81). There are various definitions of photography but for the purpose of this study we shall limit ourselves to the following:

According to Spencer (1973), Photography is the art, science, and practice of creating durable images by recording light or other electromagnetic radiation, either chemically by means of a light -sensitive material such as photographic film, or electronically by means of an image sensor.

Also, it is a universal means of communication, a good photograph needs no translator as it fixes the mind more readily than words. It has a great advantage over the written word as is it does not need to be translated for use to anyone in the world. It can be used to make comparison, to distort information, emphasize and to document social conditions as 


\section{International Journal of Science and Research (IJSR) \\ ISSN (Online): 2319-7064 \\ Index Copernicus Value (2013): 6.14 | Impact Factor (2014): 5.611}

it registers facts, ideas, and even emotions with greater accuracy than the human eyes.

The use of photography range from commercial and press to medicine and crime detection. With the advancement of photography to microfilming, the storage and retrieval of information have been made much more convenient and space use age much reduced.

It has many uses such as for business, science, manufacturing, art, recreational purposes and mass communication, though for some people which you and i know is a popular hobby that offers job opportunities to many people in the photographic manufacturing, retailing, servicing and photo fishing.

Considering the crucial part photography play the mankind, I have a strong feeling that the art and science of photography should be accorded more practical approach than theory among all colleges training professional journalists. Photographs this day are as important as news stories. Readers take delight in reading pictures to confirm and to better understand a message.

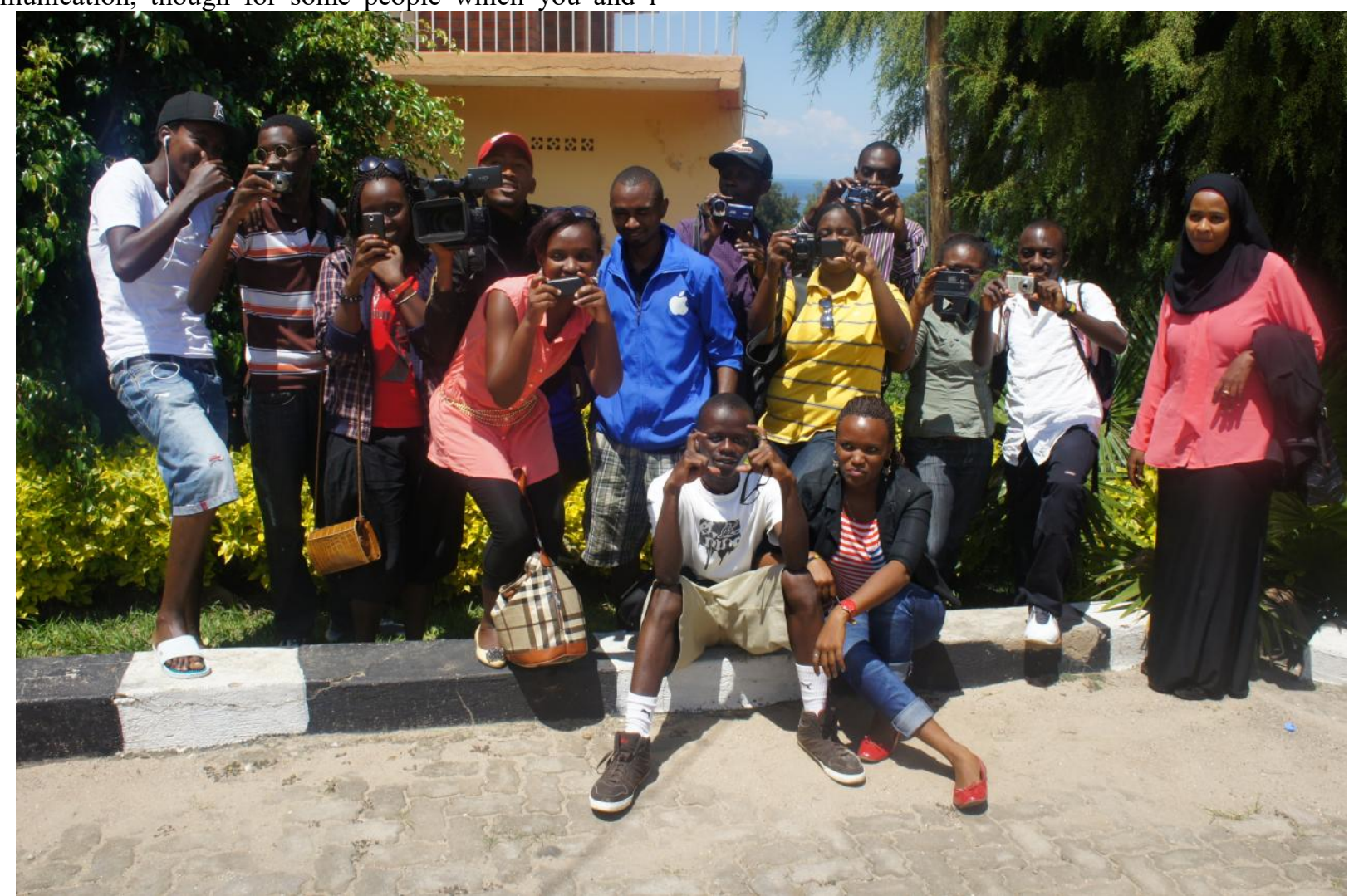

Mount Kenya University Kigali campus photojournalism students trip to Kibuye Island in Rwanda 2013.

\section{Review of Related Literature}

The Literature presented below falls into two categories, that is, the importance of photography in journalism and the challenges experienced in the professional.

\section{(a) The professional of photography in journalism course}

Since its invention in 1839, photography's unique powers of visual description have been used to record, report, and inform. People prefer to see things with their own eyes, but when this is impossible the camera can often serve the same purpose almost as well.

As the world is a construction and continues to shrink in to a global village, photography as professional in journalism has grown and its importance in the society today is inevitable and undeniable fact to be studied among colleges. Today photography is widely recognized as a fine art. Photographs are displayed in art museums, prized by collectors, discussed by critics, and studied in art history courses. Many scholars have lamented why photography is regarded as a professional:

As a nonverbal means of communication, photography can surmount the barriers of language and communicate through universal visual symbols. Photographs are well suited for use in the mass media. Today they are reproduced by the billions, and they can be found everywhere: in the pages of newspapers, magazines, books, catalogs, and brochures; on display in billboards, shop windows, and posters; broadcast over television; and organized into slide shows and film strips.

In photography's early days some of its most eagerly sought images were those brought back by explorers and travelers. These would satisfy people's curiosity about distant places like China, Egypt, and the American West. That same kind of curiosity exists today. People are fascinated with photographs of the surface of the moon, the landscape of Mars, and the appearance of other planets in the solar system. 


\section{International Journal of Science and Research (IJSR) \\ ISSN (Online): 2319-7064 \\ Index Copernicus Value (2013): 6.14 | Impact Factor (2014): 5.611}

Photographs this day are as important as news stories. Photographs in the mass-communication media have made the faces of political leaders, popular entertainers, and other celebrities familiar to the public. When a newsworthy event occurs photojournalists are there to record it. Readers take delight in reading pictures to confirm and to better understand a message. Photography is $t$ he result of combining several technical discoveries; it is a method of recording images by the action of light, or related radiation, on a sensitive material. The word was derived from the Greek words photos (Light) and graphein (to draw). In 1832, a little-known French-Brazilian inventor Hercules Florence studied ways of permanently fixing pin-hole images, which he named "photographia".

Photography is an artistic skill adopted by some as a hobby while as a professional job by others. It is only a specialized skill, but can also be a profitable one as well. Professional photographers capture amazing moments of our lives, and gain a following of fascinated viewers over their great pictures. They display their works in newspapers, art galleries and leading magazines. The art of photography as a profession nowadays has excelled to the point of providing a great development to both the world media and digital photography.

Photography as a skill is learnt through training and it is still important to learn different techniques to achieve good photography results as this also complements and enhances natural talents.

Our photographs tell us what is important to us. This impulse to save our recorded memories is a powerful force which tells us much about the role of photography in our lives and our constant desire to distil our most precious moments into images. We preserve the important events and people in our lives.

\section{Photographs allow us to share and to communicate.}

Photojournalism is communication through pictures. (Nwanyelugo and Nwadiukwu 2009:73). It is the use of photographs in the narration, description and explanation of what has happened, is happening or about to happen. The definition of photojournalism can be made clearer if we try to differentiate it from photography. Photography is just the capturing of the aesthetic (beauty) of a thing, people or event/situation in a graphic form. But photojournalism judges a photograph not merely on its beauty but how well or effective that photograph/picture is to deliver a message in a graphic term.

Images are much more than a simple record. Photography speaks to the best and most generous part of our human nature - the desire to share what we find beautiful and interesting with others. Photography makes us artists

Photojournalism is art for communication. (Nwanyelugo and Nwadiukwu 2009:74). "This implies that a photojournalist does more of the telling than a photographer. He must therefore, have a sense of news and what is important at any point in time. He must know what a news photograph should do for a publication, i.e. to arrest attention of viewers, tell the relevant story in proper perspective, and be relevant to the context of the story in every material particular."

Photography allows us to express ourselves through an art form. We notice a beautiful landscape or an old man's lined face and we want to capture it. Each of us will have a different reason to do so but, essentially, we want to create something. However humdrum our nine-to-five lives may be, the creation of an image makes us an artist. It feels good.

\section{Photography is a complex language}

Our images can express joy and sorrow, wonder and sympathy. Every human emotion can find a place in photography. Photography can be of help to some people in different ways e.g. for many years someone might never value his or her photographs of overcast landscape because I believed that there was no beauty in a land with muted colours and a leaden sky. Probably he or she wanted the land to be alive with colour and vibrancy. However, lack of colour in a landscape makes you search for other things that often go unremarked in bright sunlight. It could be asymmetry of hills or a tree standing out from a forest of thousands. So also i came across someone who has suffered from depression for most of her adult life and photography gave her a language to express feelings for which she could find no words. We have a miserably poor vocabulary for mental illness, but if photography can be allowed, in a very special it could help to develop a visual language for some of the most difficult emotions.

\section{Photography has the power to move us}

Photographs can grab our attention and speak directly to our emotions. It embodies the power of a single image. At a more subtle level, we can learn lessons about a whole range of emotions. Grief has the power to wash away the luminance and chrominance of our lives. There is no magic way to restore them at will. We have to be patient. But while waiting we can search for the shapes and patterns that are still there in the greyness. They will lead us back to colour eventually. At moments of great sorrow in my life I have used images to express that hope of returning colour. Photography, at its best, is a powerful language which speaks to our emotions. It allows us to tell our story and show others our framing of the world around us.

\section{Produce advertisements:}

Photography is also essential to the advertising industry. In efforts to sell a product, attractive photographs of the item are used. Photography is also widely used in education and training within the academic world, industry, and the armed services.

\section{b) Challenges in the studying-teaching of}

\section{Photojournalism}

Photojournalism has long been the principal visual medium through which we have come to understand important events unfolding beyond our immediate perceptual horizon. (Jason Hill) 


\section{International Journal of Science and Research (IJSR) \\ ISSN (Online): 2319-7064}

Index Copernicus Value (2013): 6.14 | Impact Factor (2014): 5.611

Photojournalism in Rwanda like many countries in Africa is still young, photographic studios begun to be active within the country in $1990 \mathrm{~s}$. Photojournalism was not considered to be a career in Rwanda until after the genocide, photographs have been used to tell the past memories.

The background culture of Rwandan that is based on storytelling and listening rather than reading and writing is a big setback for photojournalism in the country.

Lack of professional digital equipment for training the students among universities: The desire for students and lecturers to reach the digital era remain to be a challenge in universities during practical lessons. The digital professional cameras tripods and halogens are too expensive thus leaving journalism training institutions in a dilemma.

The question of how to adapt to the constantly evolving digital age is one that continues to loom even among the world's leaders in photography and photography education in Rwanda. There is a pressing need for education to embrace this as much as possible, allowing students to feel empowered to address all aspects of the medium - from manipulation techniques, to maintaining proper copyright of their images, to promoting themselves as a brand and using the myriad of social platforms out there to stay connected and network.

When it comes to branding an identity, many photography schools are responding to the digital shift by developing coursework that encourages students to maximize new tools in their practical works. While digital branding offers emerging photographers a world of opportunity, it also poses significant challenges. One crucial element that is often lacking is the awareness of how digital communications can negatively affect students' business development.

"When I see students really use photography to make sense of the world around them, when they manage to get their heads, eyes and hearts into some sort of alignment, then I know that they are connecting with the medium," Murray says.

"Most photography somehow reflects the world, documents the world, makes a comment on the world," says Ryan. "Clearly a photographer has to constantly develop their eye. Look at all the photography you can possibly look at to feed your creative mind, but then I think you have to take that vision and have something to say.

The advent of digital imaging causes us to question and redefine the nature of the photographic visual medium, just as the invention of photography caused artists to re-evaluate the nature of painting. In technique, the difference between a photograph and a painting is easily seen. Paintings are based on lines drawn by hand, while photographs are a collection of microscopic particles exposed to light in much the same fashion that our eyes respond to light. Even the most realistic of paintings do not come close to the reality captured by the photograph.

When photography first came on the scene 150 years ago, the artist Paul Delaroche exclaimed, "From this day on, painting is dead.'Painting did not die, however; instead, photography caused painters to redefine their standards and ideas of what constituted "art."

\section{Statement of the Problem}

Nguri et al (2009) states that a good professional media is a core pillar of responsible governance and strong democracy. He argues that development cannot be achieved without checks and balances. Professional media plays its role in achieving this and media workers help create a stable, peaceful and functioning society.

Boyd (1988) in Emery and Ault (2000) states that informing and enlightening the public is a difficult task. Few can succeed as practitioners in mass communications without mastering the principles and practices of broad areas of knowledge that comprise the basic ingredients of college education. Ironically Rwanda as other East African Universities has few Universities like National University of Rwanda, Catholic University of Kabgayi, Mount Kenya University and Jomo Kenyatta University offering Journalism at bachelor's level and above with photojournalism. As journalism continues to grow in Rwanda, the more the youths both female and male desires to join the field of photojournalism but in most cases, the biggest challenge is the learning equipment like digital still photo cameras are very expensive and scarce among learning institutions. Lecturers face the challenge of training over 100 students using one camera and this leads to many students graduating without proper skills and knowledge of photojournalism.

According to Ciano (2009), a specific industry must have a polished supply chain for human resources with a design for training to fit industrial specification. Media industry is not an exception to this. A particular media house only enjoys competence if it has compatible human resources in terms of talent and training.

\section{Methodology of Data Collection}

The idea of conducting this study was mooted in 2015 at Mount Kenya University Kigali campus where I work as a lecturer in photojournalism, Television production, Drama and Documentary production and radio production handling the practical lessons in the department of journalism.

The students I often supervise to do their attachment and documentaries for research inspired me and I got interest to find out the interest the status of photojournalism, the art and science of approaching it, challenges and university students' response to analog to digital photographic equipment and literature in learning photojournalism.

I used my experience as I teach photojournalism and the supervision of students for internship to observe how photojournalism is taught, as well sharing experiences with some experienced lecturers of photojournalism and journalism students who are already in the media.

The basic method of collecting data was basically practical experience in the studio and field work, observation and 


\section{International Journal of Science and Research (IJSR) \\ ISSN (Online): 2319-7064}

Index Copernicus Value (2013): 6.14 | Impact Factor (2014): 5.611

informal structured interviews. The case studies were Mount Kenya University Kigali campus 2014/2015, National University of Rwanda 2014, Jomo Kenyatta University Kigali 2015 and Kabgayi Catholic University located in the Southern Province of Rwanda, Muhanga District, Nyamabuye Sector 2015. In order to obtain facts and opinions of data for the study without suspicious and being objective, I conducted with the respondents the interviews in casual and conversational way. I would record some of their responses by adobe premiere pro on a lap top.

\section{Findings and Solutions}

The above investigation found that photojournalism course is more theoretical than practical among Universities and it's not given the first priority as television and Radio broadcasting in journalism.

The study found out that there is scarcity of lecturers who are qualified with digital practical background in photojournalism to give skills and knowledge to photo journalism students who are in most cases, many in lecturer rooms using one digital still photo camera to be taught. This trend leads to most students who are interested in photojournalism to do practice on their own in photojournalism, using the local photographers in small studios that studied also on their own or down loaded lessons via you tube. In the end these students do not get proper basics and concepts of photojournalism. The good news is that many female students are fighting hard to join the field of photojournalism.

My suggestion focuses on the recommended learning for practical aspect in photojournalism teaching as it remains to be the biggest challenge among universities in Rwanda and East Africa at large. It's always important university photo studios to be well equipped with modern digital cameras, printers, memory cards, halogens, soft wares, tripods, computers and background, code of photojournalism ethics on the notes board and among others. The art of taking photographs among students require constant practising within universities and in the field, this cannot be achieved using one camera in a studio used with over 100 students in a university. Still cameras that use un- chargeable batteries and films should be replaced with cameras that with memory cards and chargeable batteries to cut on the cost of purchasing batteries.

\section{Conclusion}

Indeed, its undeniable fact to assert that the world of photo journalism is a construction and as it continues to shrink in to a global village, most lecturers in Rwanda like the rest of Africa still face the challenge to embrace the content of analogue to digital photojournalism syllabus at university level. There is high demand of digital photojournalism for the new generation among learners and yet digital devices used in photojournalism are scarce. There is need for international digital manufacturers of cameras to make them affordable in the $3^{\text {rd }}$ world countries to enable photojournalism students access digital photography for journalism.

\section{Future Scope}

This study could be extended by looking into related topics in journalism like:

1) The challenge of becoming a broadcaster in a $3^{\text {rd }}$ world country.

2) The role of teaching development journalism

3) The relevance of video editing in a journalism course.

4) The benefits of training as a Media PR

\section{References}

[1] Nwanyelugbo, $\mathrm{O}$ and Nwaudiukwu I. (2000) perspectives in photography and photojournalismNsukka, Nigeria: Price publishers.

[2] Orumu A.A. (2009): Ethics and photojournalism issues in Nigerian journalist practice Markudi: Macroteacher and Associates.

[3] Batchen, Geoffrey. "Phantasm: Digital Imaging and the Death of Photography." Aperture136 (1994): 47-50.

[4] Batkin, Norton. Photography and Philosophy. Harvard Dissertations in Photography. Ed. Robert Nozickand Arthur Kingsley. New York: Garland Publishing, 1990.

[5] Charles Nandi (2006-05-04), Print Media and Photojournalism Butter Worth and Heinemann.

[6] Kobre Kenneth, (2000) Photojournalism: The Professionals' Approach, $5^{\text {th }}$ Edition Wadsworth Publishing Company.

[7] Balakrishna Aiyer (2005), Digital Photojournalism Wadsworth Publishing Company.

[8] Ojomo, O.W (2008). Introductory Photography and Photojournalism. Lagos Coronate Books.

[9] Rothstein, A.(1979). Photojournalism, Garden city, New York: American photographic book publishing Co. Inc 